\title{
Thermoelectric properties of aluminum compound-doped $\alpha$-SiC ceramics
}

\author{
Chul-Hoon PAI ${ }^{\dagger}$ \\ Department of Nano-Bioengineering, Incheon National University, Incheon 406-772, Korea
}

\begin{abstract}
The effects of aluminum compound additive on the thermoelectric properties of $\alpha$-SiC ceramics were studied. Porous SiC ceramics with $50-60 \%$ relative density were fabricated by sintering the pressed $\alpha$-SiC powder compacts with $\mathrm{AlN}$ and/or $\mathrm{Al}_{4} \mathrm{C}_{3}$ at $2150^{\circ} \mathrm{C}$ for $3 \mathrm{~h}$ in Ar atmosphere. The sintered bodies were analyzed by means of XRD, SEM, and TEM. The lattice parameter measurements revealed incorporation of a certain amount of added $\mathrm{Al}$ and/or $\mathrm{N}$ into the $\mathrm{SiC}$ lattice. $6 \mathrm{H}$ to $4 \mathrm{H}$ reverse phase transformation occurred during sintering. The Seebeck coefficient, electrical conductivity and thermal conductivity were measured at $550-950^{\circ} \mathrm{C}$ in $\mathrm{Ar}$ and/or vacuum atmosphere. The kind of additives and the amount of addition had significant effects on the thermoelectric properties. The thermoelectric figure of merit of aluminum compound-doped SiC increased with increasing temperature and was lower than that of n-type SiC. On the whole, AIN-doped SiC had higher figure of merit than $\mathrm{Al}_{4} \mathrm{C}_{3}$-doped $\mathrm{SiC}$.
\end{abstract}

(C2014 The Ceramic Society of Japan. All rights reserved.

Key-words : $\alpha$-SiC, $\mathrm{AlN}, \mathrm{Al}_{4} \mathrm{C}_{3}$, Electrical conductivity, Seebeck coefficient, Thermal conductivity, Figure of merit

[Received April 22, 2014; Accepted July 14, 2014]

\section{Introduction}

Thermoelectric energy conversion utilizing nuclear heat sources has been employed for several decades to generate power for deep space probes. The development of thermoelectric materials has recently been resurrected once again for applications such as high-temperature thermoelectric power generation. For effective utilization of solar heat, nuclear energy and waste heat from industries, materials possessing high thermoelectric energy conversion efficiency and usable at high temperatures are intensely required.

The goodness of a semiconductor in thermoelectric conversion is given by its so-called figure of merit, $\mathrm{Z}$, and is expressed by $\mathrm{Z}=\sigma \alpha^{2} / \kappa$, where $\sigma$ is the electrical conductivity, $\alpha$ is the Seebeck coefficient and $\kappa$ is the thermal conductivity. For developing thermoelectric materials, a large number of work have been concentrated on increasing the figure of merit, $\mathrm{Z}$ by increasing the electrical conductivity and Seebeck coefficient with reduction of thermal conductivity.

Generally, the thermoelectric materials can be classified into three classes by the temperature which indicates the maximum value of figure of merit; the low (r.t. $\left.-100^{\circ} \mathrm{C}\right)$, middle $\left(200-600^{\circ} \mathrm{C}\right)$ and high (above $700^{\circ} \mathrm{C}$ ) temperature materials. Compound semiconductors, such as $\mathrm{Bi}_{2} \mathrm{Te}_{3}, \mathrm{PbTe}$, and their solid solutions, have already been commercially applied to both refrigeration and power generation. ${ }^{1)}$ However, the materials so far developed are easily oxidized, decomposed, or melt above $1000^{\circ} \mathrm{C}$ and are not suitable for high-temperature applications.

Silicon carbide is now being considered for high-temperature structural applications because of its extrime hardness, excellent thermal and mechanical properties, and high thermal shock resistance. Furthermore, silicon carbide is considered to be a potentially useful material for high-temperature electronic devices as its band gap is large compared to silicon and the p-type and/or

\footnotetext{
Corresponding author: C.-H. Pai; E-mail: paichlab@incheon.ac.kr
}

n-type conduction can be controlled by impurity doping.

Porous $\mathrm{n}$-type $\mathrm{SiC}$ ceramics fabricated from $\beta$-SiC powder have been found to show high thermoelectric conversion efficiency at $800-1000^{\circ} \mathrm{C}^{2), 3)}$ Electrical conductivity of porous ntype $\mathrm{SiC}$ was comparable to or even higher than the reported values of single crystals, while thermal conductivity was kept as low as $1 / 10$ to $1 / 30$ of that for a dense ceramic. ${ }^{4)}$ It was pointed out that microstructural inhomogeneities would have significant effects on thermoelectric properties and microstructure control would become an unavoidable problem in materials development for thermoelectric energy conversion.

In this work, thermoelectric properties of p-type $\mathrm{SiC}$ ceramics fabricated from $\alpha$-SiC powder were investigated. AlN and/or $\mathrm{Al}_{4} \mathrm{C}_{3}$ were used as additives for controlling carrier concentration, and their effects on the thermoelectric conversion efficiency of $\mathrm{SiC}$ ceramics were studied.

\section{Experimental procedure}

\subsection{Fabrication of porous SiC ceramics and their} characterization

A commercial $\alpha$-SiC powder (Cerac Inc., purity; 99\% up, average particle size; $\sim 0.4 \mu \mathrm{m}$ ) and aluminum compound additives $(0-5$ mass $\%)$ were mixed by ball-milling(Y-TZP balls/alumina jar) process. AlN (Cerac Inc., purity; 99\%, -200 mesh) and/or $\mathrm{Al}_{4} \mathrm{C}_{3}$ (Cerac Inc., purity; 99\%, -325 mesh) were employed as additives. Porous $\mathrm{SiC}$ ceramics with $50-60 \%$ relative density were fabricated by sintering the pressed powder mixture compacts (compaction pressure; $200 \mathrm{~kg} / \mathrm{cm}^{2}$ ) at $2150^{\circ} \mathrm{C}$ for $3 \mathrm{~h}$ in $\mathrm{Ar}$ atmosphere. The relative density was calculated from a measured apparent density. X-ray diffraction (XRD) analysis was performed to examine the phases present and precise lattice parameters of the sintered body were measured using $\mathrm{Cu} \mathrm{K}_{\alpha}$ radiation with $\mathrm{Ni}$ filter and high-purity silicon as an internal standard. Scanning electron microscope (SEM) and Transmission electron microscope (TEM) observations were carried out to examine the microstructure of sintered bodies. 


\subsection{Measurements of thermoelectric property}

Four grooves were put on a rectangular specimen. Heads of the two Pt-Pt $13 \% \mathrm{Rh}$ thermocouples were embedded in the drilled holes at the two ends of a specimen and they were held in place with Pt wires placed along the grooves. The electrical conductivity and thermoelectric power were measured simultaneously for the same specimen at $550-950^{\circ} \mathrm{C}$ in $\mathrm{Ar}$ atmosphere. Electrical conductivity was measured using a d.c. four-probe technique. Ohm's law was always checked by changing the current value. The average voltage drop obtained from forward/reverse current directions was used to calculate the conductivity. For thermoelectromotive force measurements, a temperature gradient in the specimen was generated by flowing cool air in an alumina protection tube placed near the one end of the specimen. The temperature difference between the two ends was controlled to be 5 to $10 \mathrm{~K}$ by varying the flow rate of air. Plots of thermoelectromotive force vs. temperature difference gave rise to a straight line in all cases, and the Seebeck coefficient was calculated from its slope.

Thermal diffusivity and specific heat capacity were measured by a usual laser flash method. One side of a disc specimen cut out from a sintered body was pasted with glassy carbon for effective absorption of the laser energy. A thermocouple was fixed on the rear side to measure the temperature rise after the flash of laser pulse. Thermal diffusivity and specific heat capacity were measured separately at $550-950^{\circ} \mathrm{C}$ in vacuum. Calibration of the apparatus was carried out using a sapphire single crystal before each measurement. The thermal conductivity was calculated from thermal diffusivity, specific heat capacity, and density.

\section{Results and discussion}

\subsection{Thermoelectric properties of aluminum com- pound-doped $\alpha$-SiC}

Microstructure variation with varying the amount of additive is expressed in terms of the relative density and porosity as shown in Table 1. It can be seen that the change of relative density and porosity was little occurred in the case of AIN doping and occurred slightly in the case of $\mathrm{Al}_{4} \mathrm{C}_{3}$ doping. The SEM observations (Fig. 1) revealed that the grain size increases slightly in the case of AlN doping and little changed in the case of $\mathrm{Al}_{4} \mathrm{C}_{3}$ doping. It might be affected by aluminum and/or nitrogen incorporated during the sintering process. Silicon Carbide is produced commercially with $>95 \%$ theoretical density when boron(B) and carbon $(\mathrm{C})$ are added. Prochazka ${ }^{5)}$ has suggested that B promotes solid-state sintering by segregating selectively in grain boundaries and excess B produces a B-rich phase at the grain boundaries. However, in this study, mass transfer for grain growth would become suppressed by the strain due to the doped aluminum and/ or nitrogen.
Figure 2 shows the temperature dependence of the Seebeck coefficient for the undoped and/or doped specimens. The Seebeck coefficients for all doped specimens were positive ( $p$ type semiconducting) due to a dominant effect of the acceptor impurity, $\mathrm{Al}$ and that of the undoped specimen was also positive possibly due to a effect of the acceptor impurities (Al, Fe) contained in the starting powder. It can be also seen in Fig. 2 that the Seebeck coefficients for all doped specimens are larger than that of undoped specimen. This might be due to microstructure homogeneity. The present author has already analysed the observed abnormal temperature dependence of the Seebeck coefficient in terms of the phonon-drag effect. ${ }^{6}$ ) That is, a decrease in the stacking fault density accompanied by grain growth and crystallite growth must have increased the phonon mean free path, enhancing the phonon-drag effect leading to an apparently larger Seebeck coefficient. The TEM observations (Fig. 3) revealed that the stacking fault density decreases by $\mathrm{AlN}$ and/or $\mathrm{Al}_{4} \mathrm{C}_{3}$ doping.

It can be also seen in Fig. 2 that the Seebeck coefficients for AlN-doped specimens are apparently larger than that of $\mathrm{Al}_{4} \mathrm{C}_{3}$ doped specimens. This might be due to the stacking fault density and carrier concentration. It can be seen in Fig. 3 that the stacking fault density of AlN-doped specimen is slightly lower than that of $\mathrm{Al}_{4} \mathrm{C}_{3}$-doped specimen. Generally, the Seebeck coefficient decreases with increasing carrier concentration. Accordingly, the compensation of acceptor $(\mathrm{Al})$ and donor $(\mathrm{N})$ in the case of AlN doping leads to an apparently larger Seebeck coefficient. It can be also seen in Fig. 2 that the Seebeck coefficients deceased with increasing the amount of additives addition caused by carrier concentration.

The results of the lattice parameter measurements for undoped and/or doped specimens showed in Table 2 that a and $\mathrm{c}$ of main phase $(6 \mathrm{H}-\mathrm{SiC})$ are all larger than the standard value $(\mathrm{a}$; $0.30806 \mathrm{~nm}, \mathrm{c} ; 1.51173 \mathrm{~nm}),{ }^{4)}$ it possibly due to incorporation of the impurities $(\mathrm{Al}, \mathrm{Fe})$ contained in the starting powder into the $\mathrm{SiC}$ lattice. Furthermore, it can be also seen in Table 2 that a and c of $\mathrm{Al}_{4} \mathrm{C}_{3}$-doped specimens are generally larger than those of AlN-doped specimens and little changed with amount of additive

Table 2. Lattice Parameters of $\mathrm{SiC}$ Sintered at $2150^{\circ} \mathrm{C}$ for $3 \mathrm{~h}$ in $\mathrm{Ar}$ Atmosphere

\begin{tabular}{lcc}
\hline Sample & \multicolumn{2}{c}{ Lattice Parameter $(\mathrm{nm})$} \\
\cline { 2 - 3 } No. & $\mathrm{a}$ & $\mathrm{c}$ \\
\hline $\mathrm{N}$ & 0.30821 & 1.51237 \\
$\mathrm{AN} 1$ & 0.30832 & 1.51245 \\
$\mathrm{AN} 3$ & 0.30834 & 1.51248 \\
$\mathrm{AC} 1$ & 0.30843 & 1.51259 \\
$\mathrm{AC} 3$ & 0.30847 & 1.51257 \\
\hline
\end{tabular}

Table 1. Relative Densities and Porosities for the Specimens

\begin{tabular}{|c|c|c|c|c|c|c|c|}
\hline \multirow{2}{*}{$\begin{array}{c}\text { Sample } \\
\text { No. }\end{array}$} & \multicolumn{5}{|c|}{ Sintering Conditions } & \multicolumn{2}{|c|}{ Sintered Body } \\
\hline & Additive & $\begin{array}{c}\text { Content } \\
\text { (mass \%) }\end{array}$ & $\begin{array}{l}\text { Temp. } \\
\left({ }^{\circ} \mathrm{C}\right)\end{array}$ & $\begin{array}{l}\text { Time } \\
\text { (h) }\end{array}$ & Atmosphere & $\begin{array}{c}\text { R.D. } \\
(\%)\end{array}$ & $\begin{array}{c}\text { Porosity } \\
(\%)\end{array}$ \\
\hline $\mathrm{N}$ & - & - & \multirow{9}{*}{2150} & \multirow{9}{*}{3} & \multirow{9}{*}{$\mathrm{Ar}$} & 52.12 & 23.45 \\
\hline AN1 & \multirow{4}{*}{ AlN } & 0.5 & & & & 50.18 & 23.06 \\
\hline AN2 & & 1 & & & & 49.94 & 23.49 \\
\hline AN3 & & 3 & & & & 53.03 & 20.41 \\
\hline AN4 & & 5 & & & & 52.32 & 22.57 \\
\hline $\mathrm{AC} 1$ & \multirow{4}{*}{$\mathrm{Al}_{4} \mathrm{C}_{3}$} & 0.5 & & & & 59.15 & 17.17 \\
\hline $\mathrm{AC} 2$ & & 1 & & & & 59.59 & 17.13 \\
\hline $\mathrm{AC} 3$ & & 3 & & & & 58.07 & 18.14 \\
\hline $\mathrm{AC} 4$ & & 5 & & & & 55.27 & 20.21 \\
\hline
\end{tabular}



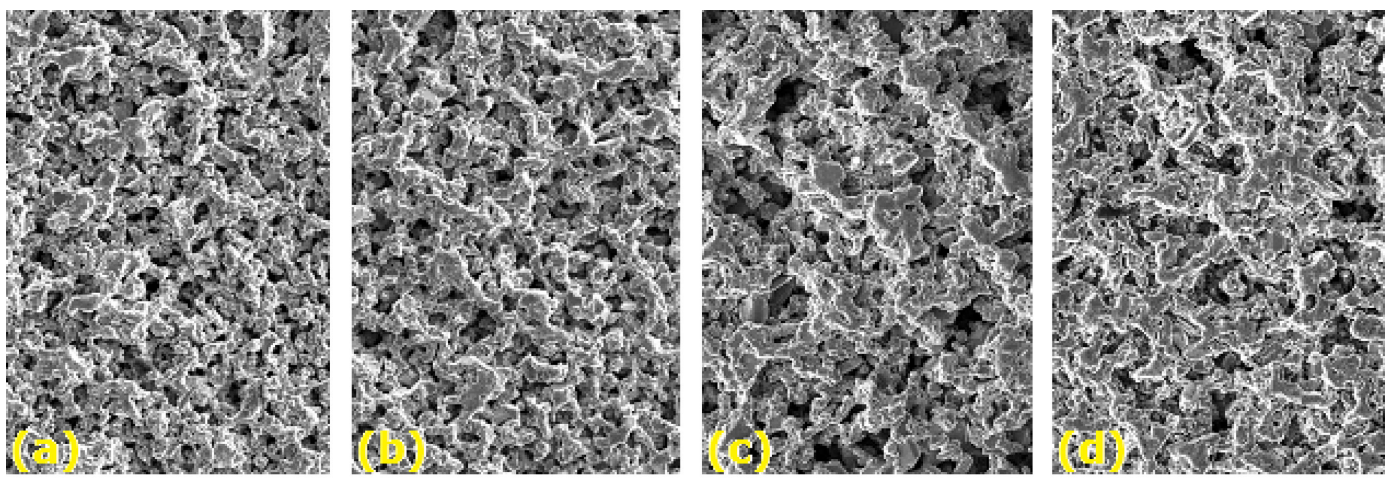

\section{- $50 \mu \mathrm{m}$}
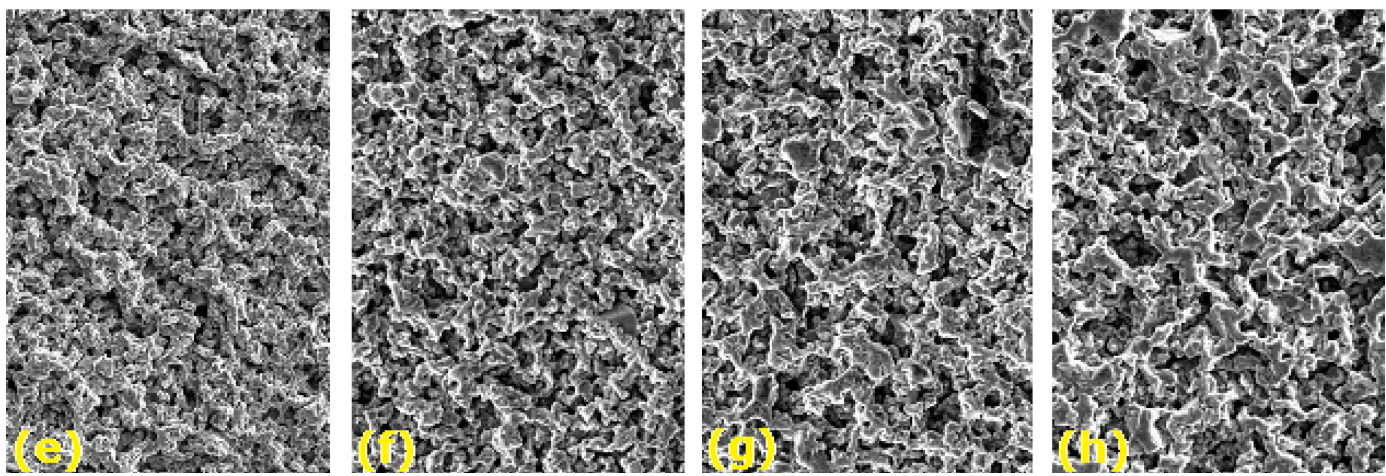

Fig. 1. Scanning electron micrographs of $\mathrm{SiC}$ sintered at $2150{ }^{\circ} \mathrm{C}$ for $3 \mathrm{~h}$ in $\mathrm{Ar}$ atmosphere; (a) undoped, (b) $1 \mathrm{mass} \% \mathrm{AlN}$, (c) 3 mass $\% \mathrm{AlN}$, (d) 5 mass $\% \mathrm{AlN}$, (e) 0.5 mass $\% \mathrm{Al}_{4} \mathrm{C}_{3}$, (f) 1 mass $\% \mathrm{Al}_{4} \mathrm{C}_{3}$, (g) 3 mass $\% \mathrm{Al}_{4} \mathrm{C}_{3}$, and (h) $5 \mathrm{mass}_{\%} \mathrm{Al}_{4} \mathrm{C}_{3}$ addition.

addition, which was expected since the covalent radius of $\mathrm{Al}$ $(0.118 \mathrm{~nm})$ is larger than that of $\mathrm{Si}(0.111 \mathrm{~nm})$ in the case of $\mathrm{Al}_{4} \mathrm{C}_{3}$ doping. And this might be due to the effect of $\mathrm{N}(0.075 \mathrm{~nm})$ replaced $\mathrm{Si}$ and/or $\mathrm{C}(0.077 \mathrm{~nm})$ in the case of AlN doping. Slake et al. ${ }^{7)}$ reported that the $\mathrm{N}$ is incorporated into the $\mathrm{C}$ at low $\mathrm{N}$ concentrations of $10^{16} \mathrm{~cm}^{-3}$ and may also replace some $\mathrm{Si}$ at a level of $>2 \times 10^{20} \mathrm{~cm}^{-3}$.

Figure 4 shows the temperature dependence of electrical conductivity. It can be seen that electrical conductivity for all doped specimens are higher than that of undoped specimen, which must be due to the change in carrier concentration. It can be also seen in Fig. 4 that $\mathrm{Al}_{4} \mathrm{C}_{3}$-doped specimens have generally higher electrical conductivity than AlN-doped specimens, except for the result of 5 mass $\%$ addition and this might be due to the difference in carrier concentration, phase composition, and microstructure.

In the case of AlN doping [Fig. 4(a)], it appeared that electrical conductivity increased with increasing the amount of AlN addition. This might be due to the effect of $6 \mathrm{H}$ to $4 \mathrm{H}$ reverse phase transformation. The hole mobility of $4 \mathrm{H}-\mathrm{SiC}$ is higher than that of $6 \mathrm{H}-\mathrm{SiC}^{6}{ }^{6}$ In the case of $\mathrm{SiC}$, cubic $\beta$-SiC stabilized by doped$\mathrm{N}$ and hexagonal $\alpha$-SiC stabilized by doped-B and $-\mathrm{Al}^{8{ }^{8-10}}{ }^{-1}$ Specially, $6 \mathrm{H}$ to $4 \mathrm{H}$ reverse phase transformation occurs by doped-Al at high temperature. ${ }^{11), 12)}$ In this study, it can be seen Fig. 5 that the peak of $4 \mathrm{H}$ phase increases and that of $6 \mathrm{H}$ phase decreases with increasing the amount of AIN addition. And electrical conductivity of 5 mass $\%$ AlN-doped specimen was higher, it might be explained from the view point of the microstructure. That is, 5 mass $\%$ added specimen has the best grain-to-grain connectivity among three kinds of specimens [Figs. 1(b)-1(d)]. This result is consistent with the previous report ${ }^{5}$ that electrical conductivity of n-type $\beta$-SiC increases with increasing compac- tion pressure, that is, the grain-to-grain connectivity of $\beta$-SiC became larger as increasing compaction pressure without noticeable change of relative density and average grain size. Better grain-to-grain connectivity must have played a role partly in increasing conductivity.

On the other hand, in the case of $\mathrm{Al}_{4} \mathrm{C}_{3}$ doping, it appeared that electrical conductivity of 1 mass $\%$ added specimen was higher and decreased with increasing the amount of $\mathrm{Al}_{4} \mathrm{C}_{3}$ addition. This might be due the difference in carrier concentration and microstructure. A polycrystalline material is composed of small crystallites joined together by grain boundaries. The grain boundary is a complex structure, usually consisting of a few atomic layers of disordered atoms. Seto ${ }^{13)}$ reported that the electrical transport properties of polycrystalline silicon films are governed by carrier trapping at the grain boundary. That is, the trapping states are capable of trapping carries and thereby immobilizing them. This reduces the number of free carriers available for electrical conduction. Consequently, in this study, electrical conductivity of $\mathrm{Al}_{4} \mathrm{C}_{3}$-doped specimens decreased with increasing the amount of excess $\mathrm{Al}_{4} \mathrm{C}_{3}$ segregated in grain boundaries. It can be also seen in Fig. 6 that the effect of $6 \mathrm{H}$ to $4 \mathrm{H}$ reverse phase transformation was smaller than the case of AlN doping.

\subsection{Thermoelectric energy conversion by porous $\mathrm{SiC}$ with aluminum compound addition}

For the purpose of materials design for thermoelectric energy conversion, it is convenient to define a figure of merit $(Z)$ for an individual material as $\mathrm{Z}=\sigma \alpha^{2} / \kappa$. That is, to increase thermoelectric energy conversion efficiency, a material having high electrical conductivity, large Seebeck coefficient, and low thermal conductivity is need. Thermal conductivity of a sintered body is generally influenced by its density and purity. ${ }^{14)}$ It can be seen in 
Fig. 7 that thermal conductivity of porous $\mathrm{SiC}$ ceramics with $\mathrm{AlN}$ and/or $\mathrm{Al}_{4} \mathrm{C}_{3}$ addition is lower than about $1 / 10$ of the values for dense $\mathrm{SiC}$ ceramics. ${ }^{14)}$

Figure 8 shows the temperature dependence of a figure of merit calculated using the data shown in Figs. 2, 4, and 6. The figure of
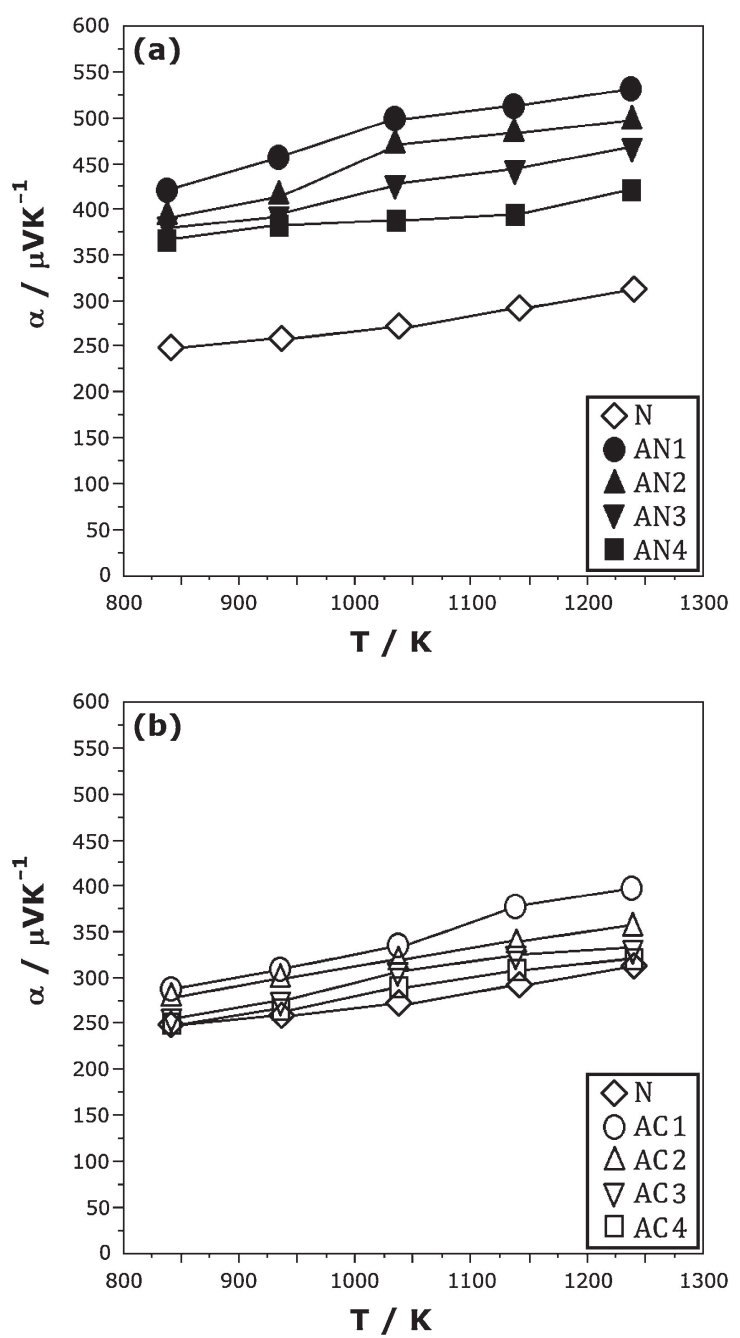

Fig. 2. Temperature dependence of the Seebeck coefficient for $\mathrm{SiC}$ sintered at $2150^{\circ} \mathrm{C}$ for $3 \mathrm{~h}$ in $\mathrm{Ar}$ atmosphere; (a) $\mathrm{N}$ (undoped), AN1 $(0.5$ mass $\%$ AlN), AN2 ( 1 mass \% AlN), AN3 ( 3 mass \% AlN), AN4 (5 mass \% AlN), and (b) $\mathrm{N}$ (undoped), $\mathrm{ACl}\left(0.5\right.$ mass $\left.\% \mathrm{Al}_{4} \mathrm{C}_{3}\right), \mathrm{AC} 2$ (1 mass \% $\left.\mathrm{Al}_{4} \mathrm{C}_{3}\right), \mathrm{AC} 3$ ( 3 mass $\left.\% \mathrm{Al}_{4} \mathrm{C}_{3}\right), \mathrm{AC} 4\left(5\right.$ mass $\% \mathrm{Al}_{4} \mathrm{C}_{3}$ ). merit increased with increasing temperature. However, $\mathrm{Al}_{4} \mathrm{C}_{3^{-}}$ doped specimen has somewhat lower figure of merit than AlNdoped specimen, since the former has very small Seebeck coefficient in comparison with the latter. On the whole, the effect of Seebeck coefficient was larger than that of electrical conductivity.

Hence it can be stated that the thermoelectric properties of p-type $\mathrm{SiC}$ ceramics could be further improved by appropriate doping and a precise control of microstructure.

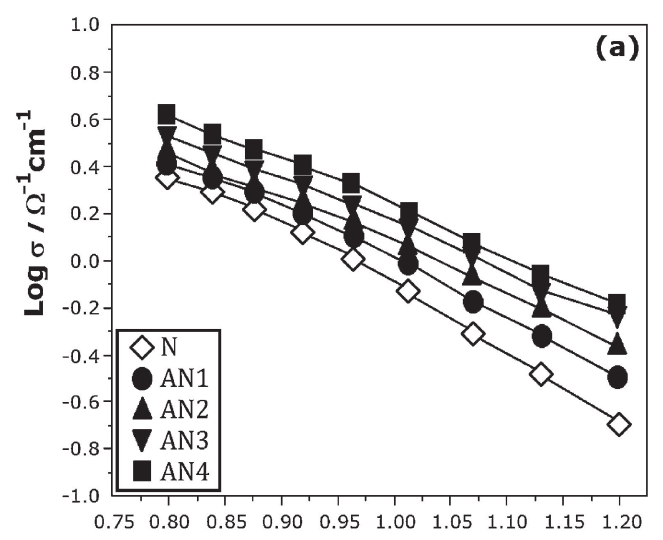

$10^{3} / \mathrm{T} / \mathrm{K}^{-1}$

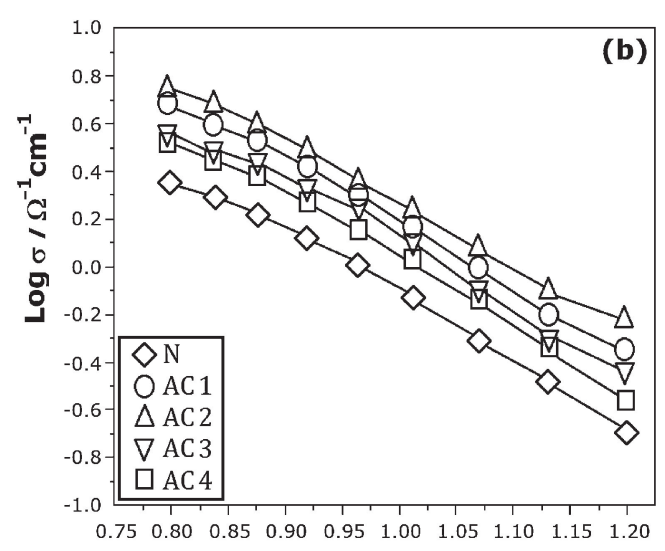

$10^{3} / \mathrm{T} / \mathrm{K}^{-1}$

Fig. 4. Temperature dependence of electrical conductivity for $\mathrm{SiC}$ sintered at $2150^{\circ} \mathrm{C}$ for $3 \mathrm{~h}$ in $\mathrm{Ar}$ atmosphere; (a) $\mathrm{N}$ (undoped), AN1 ( 0.5 mass $\%$ AlN), AN2 (1 mass \% AlN), AN3 (3 mass \% AlN), AN4 (5 mass \% AlN), and (b) $\mathrm{N}$ (undoped), $\mathrm{ACl}\left(0.5\right.$ mass $\left.\% \mathrm{Al}_{4} \mathrm{C}_{3}\right), \mathrm{AC} 2$ $\left(1\right.$ mass $\left.\% \mathrm{Al}_{4} \mathrm{C}_{3}\right), \mathrm{AC} 3$ (3 mass $\left.\% \mathrm{Al}_{4} \mathrm{C}_{3}\right), \mathrm{AC} 4\left(5\right.$ mass $\left.\% \mathrm{Al}_{4} \mathrm{C}_{3}\right)$.
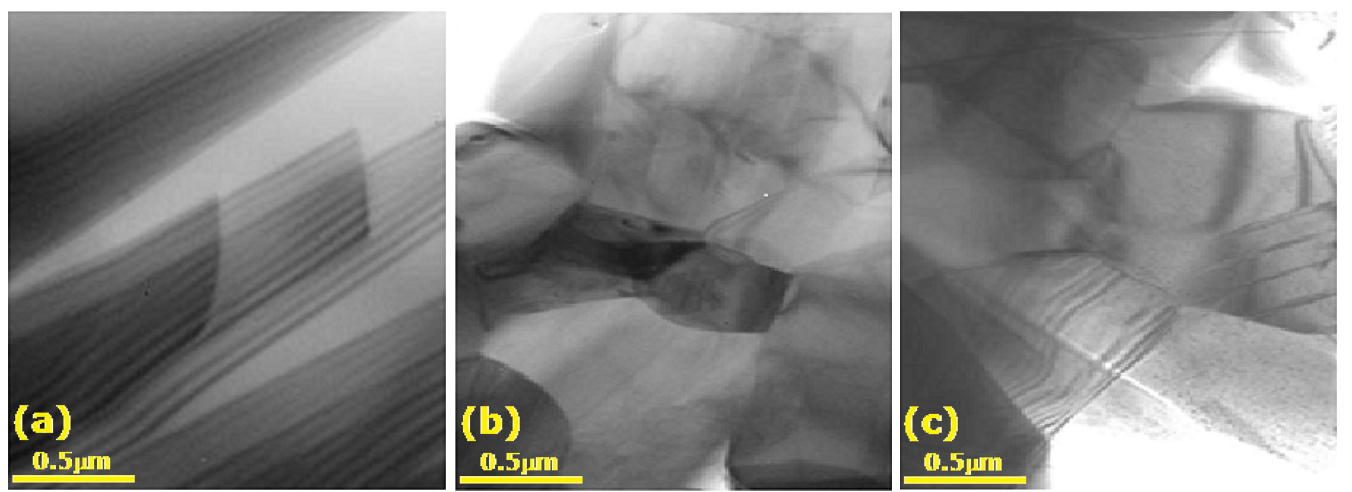

Fig. 3. Transmission electron micrographs of $\mathrm{SiC}$ sintered at $2150^{\circ} \mathrm{C}$ for $3 \mathrm{~h}$ in $\mathrm{Ar}$ atmosphere; (a) undoped, (b) 1 mass $\%$ AlN, and (c) 1 mass $\% \mathrm{Al}_{4} \mathrm{C}_{3}$ addition. 


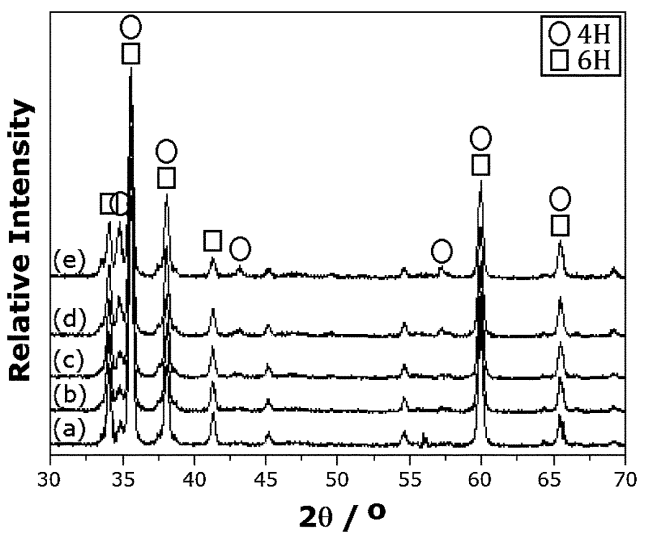

Fig. 5. X-ray powder diffraction patterns of $\mathrm{SiC}$ sintered at $2150^{\circ} \mathrm{C}$ for $3 \mathrm{~h}$ in Ar atmosphere; (a) undoped, (b) 0.5 mass \%, (c) 1 mass \%, (d) 3 mass \%, and (e) 5 mass \% AlN addition.

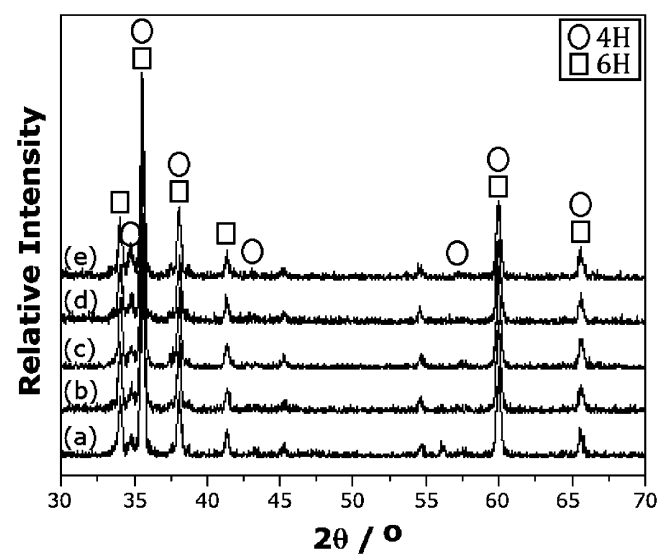

Fig. 6. X-ray powder diffraction patterns of $\mathrm{SiC}$ sintered at $2150^{\circ} \mathrm{C}$ for $3 \mathrm{~h}$ in Ar atmosphere; (a) undoped, (b) 0.5 mass \%, (c) 1 mass $\%$, (d) 3 mass $\%$, and (e) 5 mass $\% \mathrm{Al}_{4} \mathrm{C}_{3}$ addition.

\section{Conclusions}

The results of this study are summarized as follows:

(1) A certain amounts of added $\mathrm{AlN}$ and/or $\mathrm{Al}_{4} \mathrm{C}_{3}$ were incorporated into the $\mathrm{SiC}$ lattice. The Seebeck coefficients for all doped specimens were positive (p-type semiconducting) and larger than that of undoped specimen, which might be caused by microstructure homogeneity. Electrical conductivity for all doped specimens was also higher than that of undoped specimen caused by carrier concentration.

(2) The Seebeck coefficients deceased with increasing the amount of additives addition caused by carrier concentration. The specimens doped AlN were apparently larger Seebeck coefficient, which might be due to the stacking fault density and carrier concentration.

(3) In the case of AlN doping, it appeared that electrical conductivity increased with increasing the amount of AlN addition, which might be mainly due to the effect of $6 \mathrm{H}$ to $4 \mathrm{H}$ reverse phase transformation.

(4) In the case of $\mathrm{Al}_{4} \mathrm{C}_{3}$ doping, it appeared that electrical conductivity was slightly higher than that of AlN-doped caused by carrier concentration. Electrical conductivity of 1 mass $\%$ added specimen was higher and the excess addition had harmful influence upon electrical conduc-

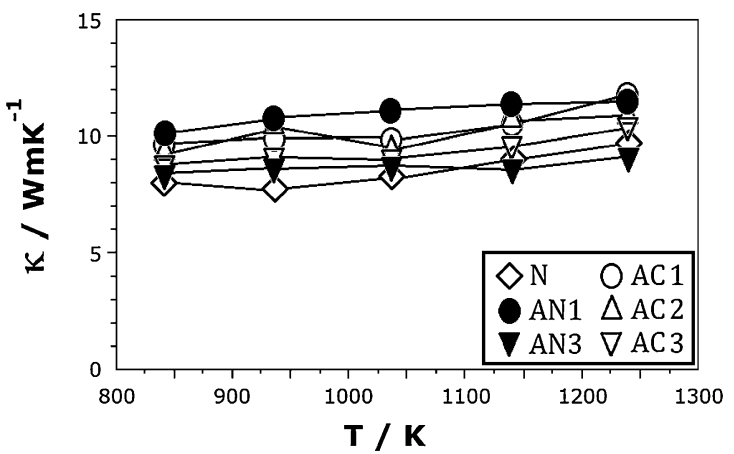

Fig. 7. Temperature dependence of thermal conductivity for SiC sintered at $2150^{\circ} \mathrm{C}$ for $3 \mathrm{~h}$ in $\mathrm{Ar}$ atmosphere; $\mathrm{N}$ (undoped), AN1 (0.5 mass \% $\mathrm{AlN}), \mathrm{AN} 3$ ( 3 mass $\% \mathrm{AlN}), \mathrm{AC} 1\left(0.5\right.$ mass $\left.\% \mathrm{Al}_{4} \mathrm{C}_{3}\right), \mathrm{AC} 2$ (1 mass $\%$ $\mathrm{Al}_{4} \mathrm{C}_{3}$ ), $\mathrm{AC} 3$ (3 mass $\% \mathrm{Al}_{4} \mathrm{C}_{3}$ ).

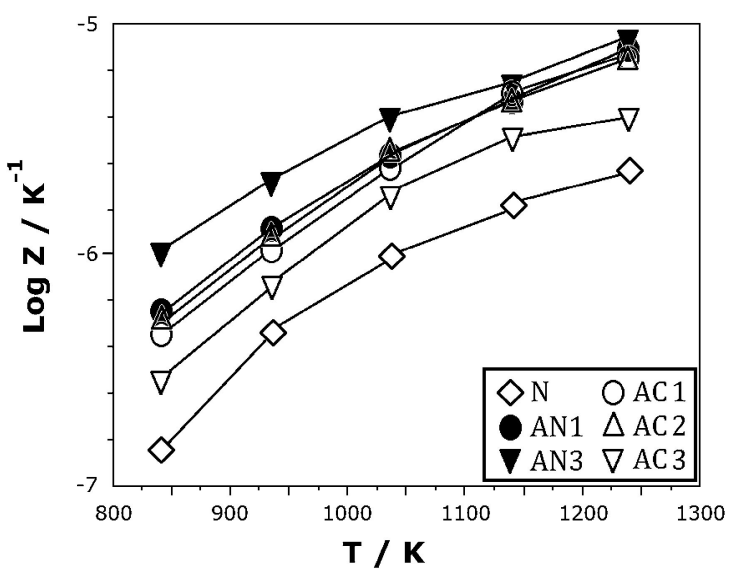

Fig. 8. Temperature dependence of the calculated figure of merit for $\mathrm{SiC}$ sintered at $2150^{\circ} \mathrm{C}$ for $3 \mathrm{~h}$ in $\mathrm{Ar}$ atmosphere; $\mathrm{N}$ (undoped), AN1 (0.5 mass \% AlN), AN3 ( 3 mass \% AlN), $\mathrm{AC} 1\left(0.5\right.$ mass $\left.\% \mathrm{Al}_{4} \mathrm{C}_{3}\right), \mathrm{AC} 2$ (1 mass \% $\mathrm{Al}_{4} \mathrm{C}_{3}$ ), $\mathrm{AC} 3$ (3 mass $\% \mathrm{Al}_{4} \mathrm{C}_{3}$ ).

tivity, which might be due the difference in carrier concentration and microstructure.

(5) Thermal conductivity of aluminum compound-doped SiC was lower than about $1 / 10$ of the values for dense $\mathrm{SiC}$ ceramics.

(6) The figure of merit of aluminum compound-doped SiC increased with increasing temperature. On the whole, AlN-doped $\mathrm{SiC}$ had higher figure of merit than $\mathrm{Al}_{4} \mathrm{C}_{3}-$ doped $\mathrm{SiC}$, since the effect of Seebeck coefficient was larger than that of electrical conductivity.

Acknowledgement This work was supported by the Research Institute of Industry-Academic Cooperation Foundation Incheon National University Research Grant in 2010.

\section{References}

1) K. Uemura and I. Nishida, "Thermoelectric Semiconductors and Their Applications," Nikkan Kogyo Shinbun-sha (1988) pp. $1-11$.

2) K. Koumoto, M. Shimohigoshi, S. Takeda and H. Yanagida, Ceram. Trans., 2, 501-510 (1989).

3) C. H. Pai, K. Koumoto, S. Takeda and H. Yanagida, Solid State Ionics, 32/33, 669-677 (1989).

4) V. Munch, "Silicon Carbide," in Landolt-Bornstein, Vol. 17a, Springer-Verlag, Berlin (1982) pp. 132-142.

5) S. Prochazka, "Special Ceramics," Vol. 6, Ed. by Popper, P., 
Brit. Ceram. Res. Assoc., Stoke-on-Trent (1975) pp. 171-181.

6) K. Koumoto, C. H. Pai, S. Takeda and H. Yanagida, Pro. 8th Inter. Conf. on Thermoelec. Energy Conversion and 2nd Europ. Conf. Thermoelectrics, Nancy, France (1989) pp. 107112.

7) G. A. Slack and R. I. Scace, J. Chem. Phys., 42, 805-806 (1964).

8) T. Kawamura, Mineral. J., 4, 333-335 (1965).

9) W. F. Knippenberg and G. Verspui, Mater. Res. Bull., 4, 45-56 (1969).
10) M. Mitomo, Y. Inomata and M. Kumanomido, J. Ceram. Soc. Japan, 78, 224-228 (1970).

11) N. W. Jepps and T. F. Page, J. Am. Ceram. Soc., 64, c-177 (1981).

12) C. H. Pai, K. Koumoto and H. Yanagida, J. Ceram. Soc. Japan, 97, 1170-1175 (1989).

13) J. Y. W. Seto, J. Appl. Phys., 46, 5247-5254 (1975).

14) T. Sakai, N. Hirosaki and T. Aikawa, "Silicon Carbide Ceramics," Uchida Rokakuho Press, Tokyo (1988) pp. 201210 . 